\title{
CHEMICAL COMPOSITIONS OF PINE RESIN, ROSIN AND TURPENTINE OIL FROM WEST JAVA
}

\author{
Bambang Wiyono ${ }^{1}$, Sanro Tachibana ${ }^{2}$ and Djaban Tinambunan ${ }^{1}$
}

\begin{abstract}
This study was conducted to identify chemical composition of merkus pine resin, rosin and turpentine oil. Initially, pine resin was separated into neutral and acidic fractions with an aqueous $4 \%$ sodium hydroxide solution. After methylation, the fraction containing turpentine oil and rosin were analyzed by gas chromatography (GC), and gas chromatograph mass spectrometry (GC-MS), respectively. The neutral fraction of pine resin and turpentine oil mainly consisted of $\alpha$-pinene, $\Delta-3$ carene and $\beta$-pinene. Based on mass spectral comparison, the major constituents of the acidic fraction and rosin were identified as sandaracopimaric acid, isopimaric acid, palustric acid, dehydroabietic acid, abietic acid, neoabietic acid, and merkusic acid. The major component of the acidic fractions was palustric acid, while that of rosin was abietic acid. Using TC (tough column) 1 and TC 5 columns, levopimaric acid could not be separated from rosin or acidic fraction of pine resin of Indonesian Pinus merkusii.
\end{abstract}

Keywords: Pinus merkusii, turpentine oil, rosin, neutral fraction, acidic fraction

\section{INTRODUCTION}

Pinus merkusii has been used for reforestation in Indonesia since a long time. Its wood is utilized as raw material for pulp and paper industries. This species also produces gum oleoresin, which is better than others and contains a high quality of turpentine oil (Sudiono, 1983).

Almost all provinces in Java Island have pine forests. Pine forest in East Java province is about 64,630 ha, covering Jombang, Lawu DS, Kediri, Blitar, Pasuruan, Probolinggo, Jember, Bondowoso, and Banyuwangi. Whereas, pine forest in Central Java is around 108,000 ha, distributed in 20 forest districts. The area of pine forest in West Java and Banten provinces is about 63,000 ha.

Pinus merkusii produces gum oleoresin, which is used as a raw material for rosin and turpentine production for international and national markets. Through distillation process, gum oleoresin is converted into rosin and turpentine. Rosin is a complex mixture that mostly contains resin acids and a little amount of neutral fraction. Rosin mostly contains abietic type (abietic, levopimaric, pallustric, neoabietic, dehydroabietic and tetra abietic acids) and pimaric type (pimaric and isopimaric acids), besides neutral components.

\footnotetext{
${ }^{1}$ Forest Products Research and Development Center, Bogor, Indonesia

${ }^{2}$ Faculty of Agriculture, Ehime University, 3-5-7 Tarumi, Matsuyama, Ehime, 790-8566 JAPAN
} 
Rosin is widely used in adhesives, printing ink, electric isolation, paper, soldering flux, varnish, and matches industries (Wiyono, 1989). In printing ink industries, rosin gives adhesiveness, surface smoothness, hardness, anti blocking, and other properties. Rosin has a good electric isolation, being used as oil in cable for high voltage electricity. In soldering process, rosin is used to get rid of oxide compound in the surface of metal, synthetic rubber, and chewing gum (FAO, 1995).

As initial step to utilize gum oleoresin, rosin and turpentine, it is needed to identify their chemical compositions, especially from Pinus merkusii. Therefore, a study was conducted to identify chemical compositions of gum oleoresin, rosin, and turpentine collected from West Java.

\section{MATERIALS AND METHODS}

\section{A. Location and Sample Collection}

This research project was conducted at the Faculty of Agriculture, Ehime University, Japan, and the Forest Product Technology Research and Development Center, Indonesia in the year 2004.

The samples of rosin, turpentine oil and pine resin of Pinus merkusii used for this study were collected from rosin and turpentine oil companies in West Java. Rosin and turpentine oil were produced through steam distillation process.

\section{B. Samples Preparation}

Approximately 1-2 $\mathrm{g}$ of each sample of the gum oleoresins was dissolved in diethyl ether, transferred to a $50-\mathrm{ml}$ separation funnel, and then added to an aqueous $4 \%$ sodium hydroxide $(\mathrm{NaOH})$ solution. After shaking, the soluble fraction was removed, and then the aqueous $4 \% \mathrm{NaOH}$ solution was added to the funnel again. The same procedure was repeated. To obtain the soluble fraction, an aqueous $8 \mathrm{~N} \mathrm{HClO}_{2}$ solution was added to make an acidic fraction and then extracted twice with diethyl ether. The ethereal solution was dried over anhydrous sodium sulfate overnight. Each fraction was obtained after evaporation of the solvent with an evaporator in vacuo. Each insoluble ethereal fraction was dried over anhydrous sodium sulfate overnight to obtain a neutral fraction after evaporation of the solvent with the evaporator in vacuo. The acidic fraction was methylated with a diazomethane ethereal solution using standard procedures. Both the acidic and neutral fractions were dissolved with chloroform and stored in a freezer prior to analysis.

\section{Gas Chromatographic Analysis of Neutral Fraction and Turpentine}

The GC analyses of neutral fraction and turpentine oil were performed using a HITACHI 3000 Gas chromatograph, equipped with an electronic Chromato-integrator D2500, a Flame Ionization Detector, an injector, and a TC-1 capillary column ( $30 \mathrm{~m}$ by $0.25 \mathrm{~mm}$ i.d., and film thickness $0.25 \mu \mathrm{m}$ ). The column temperature was $70^{\circ} \mathrm{C}$, rising at $2^{\circ} \mathrm{C} / \mathrm{min}$ to $200^{\circ} \mathrm{C}$. The carrier gas was Helium delivered at a flow rate of $1.70 \mathrm{ml} / \mathrm{min}$ with a split ratio of 1:10. The FID detector and injector port were maintained at a temperature of $230^{\circ} \mathrm{C}$. 


\section{Gas Chromatographic and Mass Spectrometry Analysis of Acidic Fractions and Rosin}

The GC analyses of acidic fraction of pine resin and rosin were performed using the same Gas chromatograph. The column temperature was $150^{\circ} \mathrm{C}$, rising at $4^{\circ} \mathrm{C} / \mathrm{min}$ to $300^{\circ} \mathrm{C}$. The carrier gas was Helium delivered at a flow rate of $1.70 \mathrm{ml} / \mathrm{min}$. The FID detector and injector port were maintained at a temperature of $260^{\circ} \mathrm{C}$ and $300^{\circ} \mathrm{C}$, respectively. Acid fraction of pine resin and rosin were also analyzed using a TC-5 capillary column ( $30 \mathrm{~m}$ by $0.25 \mathrm{~mm}$ i.d., and film thickness $0.25 \mu \mathrm{m}$ ), with the FID detector and injector port maintained at $280^{\circ} \mathrm{C}$. The column temperature was $170^{\circ} \mathrm{C}$, rising at $2.5^{\circ} \mathrm{C} / \mathrm{min}$ to $280^{\circ} \mathrm{C}$. The carrier gas was Helium delivered at a flow rate of $2.32 \mathrm{ml} / \mathrm{min}$ with a split ratio of $1: 20$. Using the same column and conditions, both acids were also analyzed isothermally at $200^{\circ} \mathrm{C}$.

\section{E. Identication and Quantification of Constituents}

The main constituents of the neutral fractions and turpentine oils were identified by comparing retention times with those of authentic samples. Results were confirmed based on relative retention indices $(\mathrm{RI})$ determined by injecting a reference mixture of $\mathrm{C} 8$ to $\mathrm{C} 16$ hydrocarbons into the GC system under the same conditions as for the analysis and calculated according to a formula in the literature (Adam, 1995, Davies, 1990, Isidorov et al., 2001).

The main constituents of the rosin and acidic fraction were identified using a Shimadzu QP 5050A Gas chromatograph Mass spectrometer. Two capillary columns (TC-1 and TC-5, $30 \times 0.25 \mathrm{~mm}$ i.d., film thickness $0.25 \mu \mathrm{m}$ ) were used for the identification. The analysis was performed using the same conditions as in the GC analysis. Many compounds were identified using Wiley libraries (seventh edition) by comparing mass spectra for the injected samples to mass spectra in the library. Some papers were also helpful for the identification of compounds (Weißmann and Lange, 1987, Weißmann, 1974, Yano and Furuno, 1994).

The quantification of constituents was conducted with a GC-FID profile obtained on a capillary column according to the peak area percent method without response factor correction (Pteifhover, 2000).

\section{RESULTS AND DISCUSSIONS}

\section{A. Turpentine Oil}

A result of analysing chemical composition of neutral fraction and turpentine oil by gas chromatography was in Table 1. Meanwhile, profile of their chromatogram could be seen in Appendices 1 and 2 . The analyses showed that both samples, neutral fraction and turpentine oil, mainly contained 8 components, covering $\alpha$-pinene, $d$-camphene, $\beta$-pinene, myrcene, $\alpha$ phellandrene, $\Delta$-carene, $\mathrm{p}$-cymene and d-limonene (Figure 1). The highest component in turpentine oil was $\alpha$-pinene, reaching $86 \%$, followed by $\Delta$-carene and $\beta$-pinene. 
Table 1. Composition of neutral fraction in pine resin and turpentine oil

\begin{tabular}{|c|l|c|c|c|}
\hline No & Constituents & NF & TPT & RI \\
\hline 1 & $\alpha$-pinene & 73.1 & 82.9 & 945 \\
2 & $d$-camphene & 0.8 & 0.9 & 954 \\
3 & $\beta$-pinene & 1.8 & 2.2 & 981 \\
4 & Myrcene & 0.7 & 0.4 & 993 \\
5 & $\alpha$-phellandrene & 0.2 & 0.4 & 1003 \\
6 & $\Delta$-carene & 16.0 & 11.0 & 1016 \\
7 & $p$-cymene & 0.8 & 1.1 & 1021 \\
8 & $d$-limonene & 1.9 & 1.3 & 1028 \\
\hline
\end{tabular}

Remarks: NF $=$ Neutral fraction; TPT $=$ Turpentine oil

$\mathrm{RI}=$ Retention indices in elution on the TC 1 column

(Equal to DB 1 and OV 1 column).

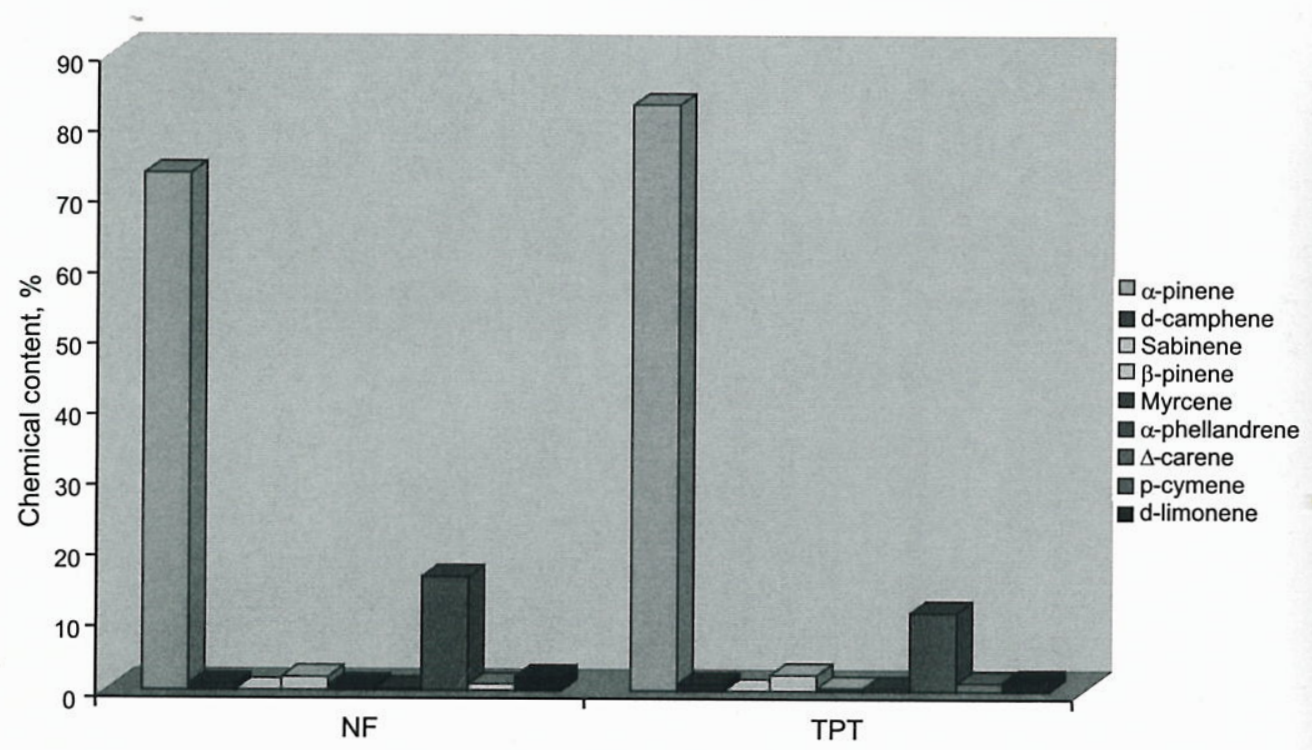

Figure 1. Histogram of chemical composition for neutral fraction in pine resin and turpentine 
Analysis result of chemical composition of neutral fraction was principally similar to that of turpentine oil. However, its main components, $\alpha$-pinene and $\beta$-pinene, were quantitatively lower than that of turpentine composition (Table 1). On the other hand, $\Delta$ carene was higher.

Compared to the chemical composition of turpentine oil of Pinus merkusii from the Philippine and Thailand, it was principally no different; the main components were also $\alpha$ pinene and $\Delta$-carene. However, quantitatively the turpentine oil from West Java contained more pinene component than that from Thailand, varied about $46-84 \%$. Compared to the turpentine oil from the Philippine, which contained pinene component more than $90 \%$, the turpentine oil from West Java contained lower pinene component, (Coppen et al., 1998).

Relating to the quality of turpentine oil, FAO (1995) mentioned that turpentine oil containing pinene component minimally $90 \%$ is the best quality, medium quality if contain $80-90 \%$ pinene component, and low quality if under $80 \%$. Based on these criteria, turpentine oil from West Java $(85 \%)$ is categorized as a medium quality.

\section{B. Acidic Fraction and Rosin}

The result of chemical analysis of rosin and acidic fraction by gas chromatography was presented in Table 2; while samples of chromatogram profile were figured in Appendices 3 and 4. In this analysis relative retention time could not be used to identify chemical components in both rosin and acidic fraction, as in identifying chemical composition of turpentine oil and neutral fraction. Therefore, further study on chemical components in rosin and acidic fraction should be to compare mass spectra of the sample component to the mass spectra in the library in GC-MS. A sample of identifying a chemical component with this method could be seen in Appendix 5. Results indicated that rosin and acidic fraction were qualitatively similar. Both rosin and acidic fraction contained methyl sandaraco pimaric, methyl isopimaric, methyl palustric, methyl dehydroabietic, methyl abietic, methyl neoabietic, and methyl merkusic acids. The highest component in rosin was methyl dehydroabietic, reaching $27-28 \%$. Meanwhile, the highest component in acidic fraction was methyl palustric acid, reaching $32-38 \%$ (Figure 2).

Table 2. Composition of acidic fractions eluted on TC 1 and TC 5 columns

\begin{tabular}{|c|l|c|c|c|c|c|c|}
\hline \multirow{2}{*}{ No. } & \multirow{2}{*}{ Constituent } & \multicolumn{3}{|c|}{ Acidic fraction, \% } & \multicolumn{3}{c|}{ Rosin, \% } \\
\cline { 3 - 8 } & & TC 1 & TC 5 a & TC 5 b & TC 1 & TC 5 a & TC 5 b \\
\hline 1 & Pimaric acid ME & - & - & & - & - & \\
2 & Sandaracopimaric acid ME & 17.1 & 7.4 & 6.9 & 12.2 & 13.7 & 13.7 \\
3 & Isopimaric acid ME & 17.1 & 19.9 & 20.0 & 17.9 & 18.5 & 18.7 \\
4 & Palustric acid ME & 32.2 & 38.2 & 33.9 & 9.7 & 9.82 & 9.9 \\
5 & Dehydroabietic acid ME & 6.7 & 7.1 & 9.3 & 27.7 & 27 & 28.1 \\
6 & Abietic acid ME & 13.2 & 14.1 & 18.0 & 17.0 & 16.2 & 15.4 \\
7 & Neoabietic acid ME & 3.2 & 3.3 & 3.6 & 1.3 & 2.37 & 3.8 \\
8 & Merkusic acid ME & 10.6 & 9.9 & 8.3 & 14.2 & 12.4 & 10.4 \\
\hline
\end{tabular}

Remarks: TC 1 and TC 5a: gradient temperature programme; TC 5b: isothermal temperature programme 
Figure 2 showed that TC 5 column, both gradient and isotherm program, eluted more methyl palustric acid than TC 1 column in an acidic fraction; while in rosin, Figure 3, both columns were almost similar to elute methyl dehydroabietic acid. Among the columns used in this research, the TC 5 column with gradient program was the best to identify chemical composition in acidic fraction. Meanwhile, the TC 1 column was the best in identifying chemical composition in rosin.

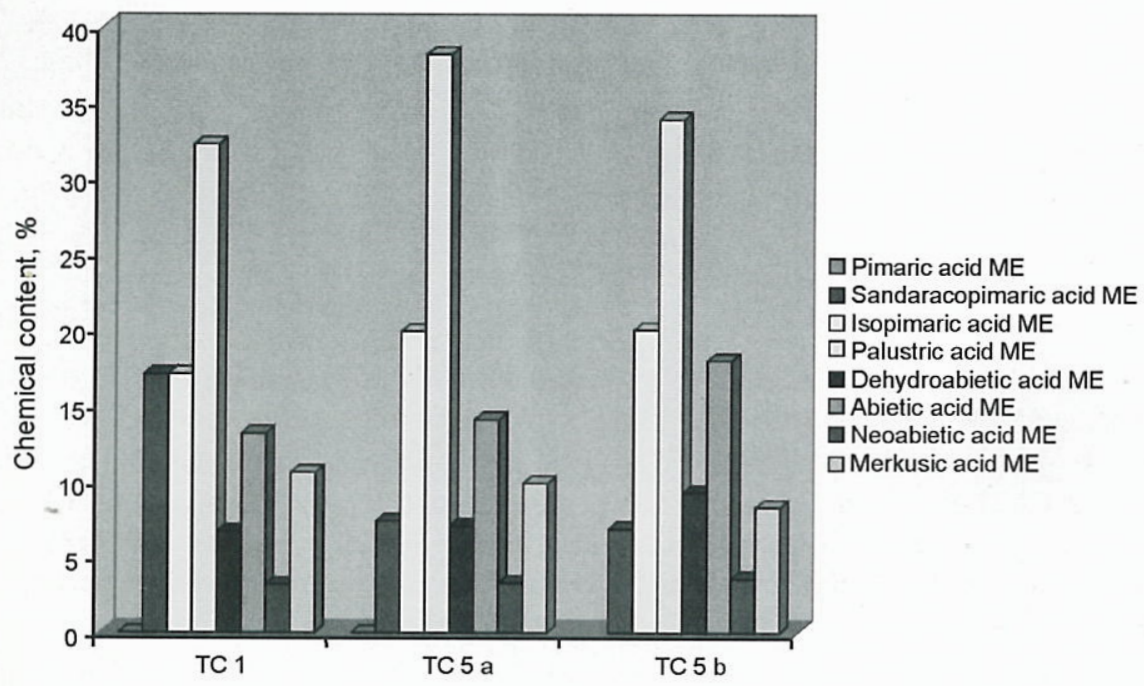

Figure 2. Histogram of chemical composition for acidic fraction

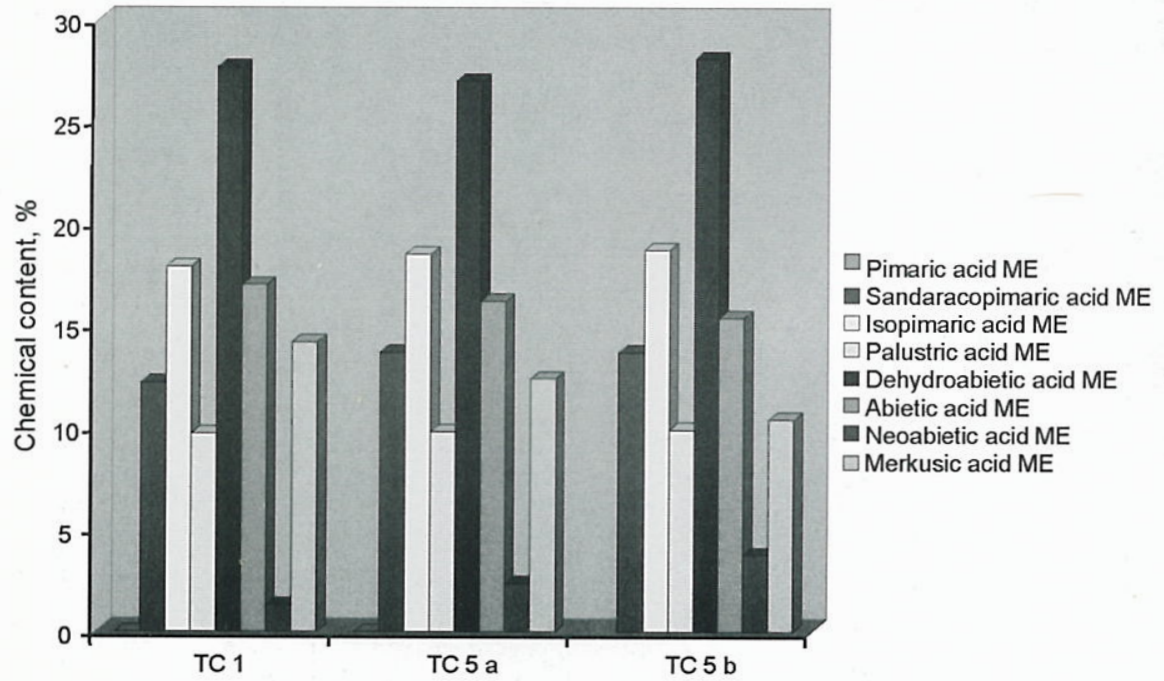

5. Figure 3. Histogram of chemical composition for rosin 
Qualitatively, chemical composition of rosin in this research was almost similar to that in previous ones (Weißmann, 1974, Weißmann and Lange, 1987, Coppen et al., 1993, Coppen et al., 1998). A little difference was in methyl levopimaric acid that did not exist in both rosin and acidic fraction. In previous studies, this component always came up together with methyl palustric acid, and they were calculated as one component. In this study, a component of methyl levopimaric acid could not be eluted using TC 1 or TC 5 column.

Relating to their utilization through modification process, three main components covering abietic acid, palustric acid and neoabietic acid were used as a raw material for the modification process. This study indicated that the total of these compounds was $50-53 \%$ in acidic fraction. Based on the dehydroabietic acid component, rosin is a good raw material for hydrogenated rosin.

\section{CONCLUSION}

1. Both turpentine oil and neutral fraction of pine resin contained $\alpha$-pinene, $d$-camphene, $\beta$ pinene, myrcene, $\alpha$-phellandrene, $\Delta$-carene, $\beta$-cymene and $\mathrm{d}$-limonene. The main components of both samples were $\alpha$-pinene, $\Delta$-3-carene, and $\beta$-pinene.

2. Chemical composition of both rosin and acidic fraction of pine resin covered methyl sandaraco pimaric, methyl isopimaric, methyl palustric, methyl dehydroabietic, methyl abietic, methyl neoabietic, and methyl merkusic acids. The highest component in rosin was methyl dehydroabietic, reaching 27-28\%. Meanwhile, the highest component in acidic fraction was methyl palustric acid, reaching $32-38 \%$.

3. Acidic fraction contained three main components covering abietic acid, palustric acid, and neoabietic acids. They were used as a raw material for the modification process. This study indicated that the total of these compounds was $50-53 \%$ in acidic fraction. Based on the dehydroabietic acid component, rosin could be categorized as a good raw material for hydrogenated rosin.

\section{REFERENCES}

Adam, R.P. 1995. Identification of essential oil constituents by Gas Chromatography/Mass Spectrometry. Allured Publishing Corporation, Carol Stream, Illinois-USA.

Coppen, J. J. W., C. Gay, D. J. James, J. M. Robinson and N. Supriana. 1993. Variability in xylem resin composition amongst natural populations of Indonesian Pinus merkusii. Phytochemistry. 33: 129-136. Elsevier Science, Ltd.

Coppen, J. J. W., C. Gay, D. J. James, J. M. Robinson and W. Subansene 1998. Variability in xylem resin composition amongst natural population of Thai and Filipino Pinus merkusii de Vriese. Flavor Fragr.J. 13: 33-39. John Wiley and Sons,Ltd.

Davies, N V. 1990. Review: Gas Chromatographic retention indices of mono terpenes and sesquiterpenes on methyl silicone and Carbowax 20M phases. J. Chromatography. 503: 1-24. Walter de agruyter, Berlin-New York. 
Isidorov, V. A., I. G. Zenkevich, U. Krajewska, E. N. Dubis, J. Jaroszynska, and K. Bal. 2001. Gas chromatographic analysis of essential oils with preliminary partition of constituents. Phytochem. Anal. 12: 8790. Elsevier Science, Ltd.

Pteifhover, H. W. 2000. Composisiton of the essential oil of Pinus canariensis Sweet ex Sprengel. Flavor and Fragr. J. 15: 266-270. John Wiley and Sons, Ltd.

Sudiono. 1983. Potensi dan penyebaran hutan pinus di Indonesia. Prosiding Simposium Pengusahaan Hutan Pinus. Kerjasama P3HH dan Perum Perhutani. Jakarta.

Weißmann, G. 1974. Merkunsinsaure, eine Dicarbonsaure in Balsam von Pinus merkusii. Holfzforchung. 28: 186-188. Walter de agruyter, Berlin-New York.

Weißmann, G. and W. Lange. 1987. Zusammensetzung der neutralteile des Balsamkolophoniums von Pinus massoniana Lamb., Pinus merkusii Jungh. Und Pinus luchuensis Mayr. Holfzforchung. 41: 147-154. Walter de agruyter, Berlin-New York.

Wiyono, B. 1989. Rosin and turpentine processes with pine stumps solvent extraction method and by products of sulfate pulping from pinewoods. Duta Rimba magazine, 103104/XV/1989. Bogor Indonesia.

Yano, S. and T. Furono. 1994. Resin acids from extracts of pine cones of Kuromatsu (Pinus thunbergii). Mokuzai Gakkaishi. 40: 72-77. 


\section{Appendix 1. Chromatogram of chemical composition of turpentine oil}

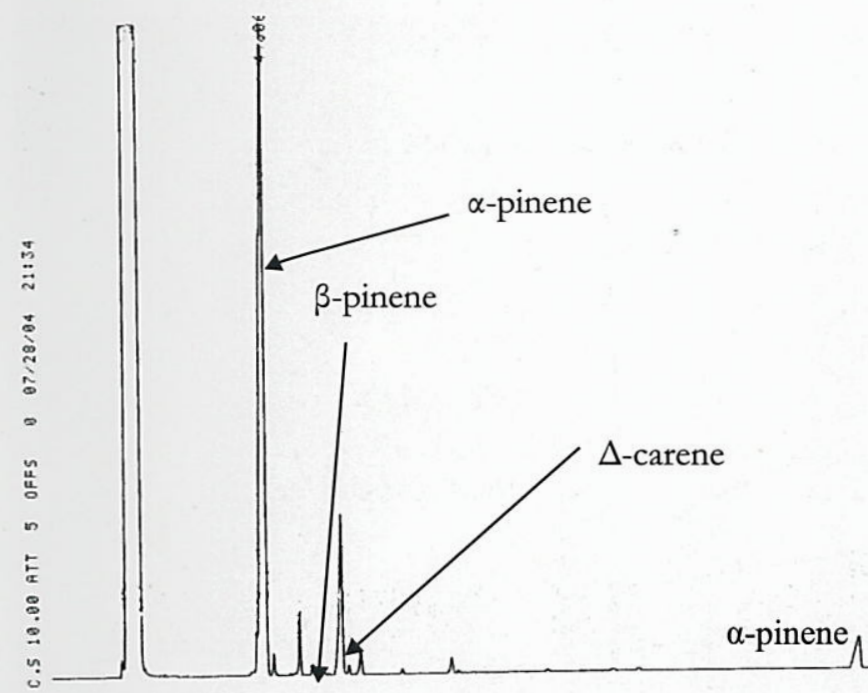

Appendix 2. Chromatogram of chemical composition for neutral fraction of pine resin

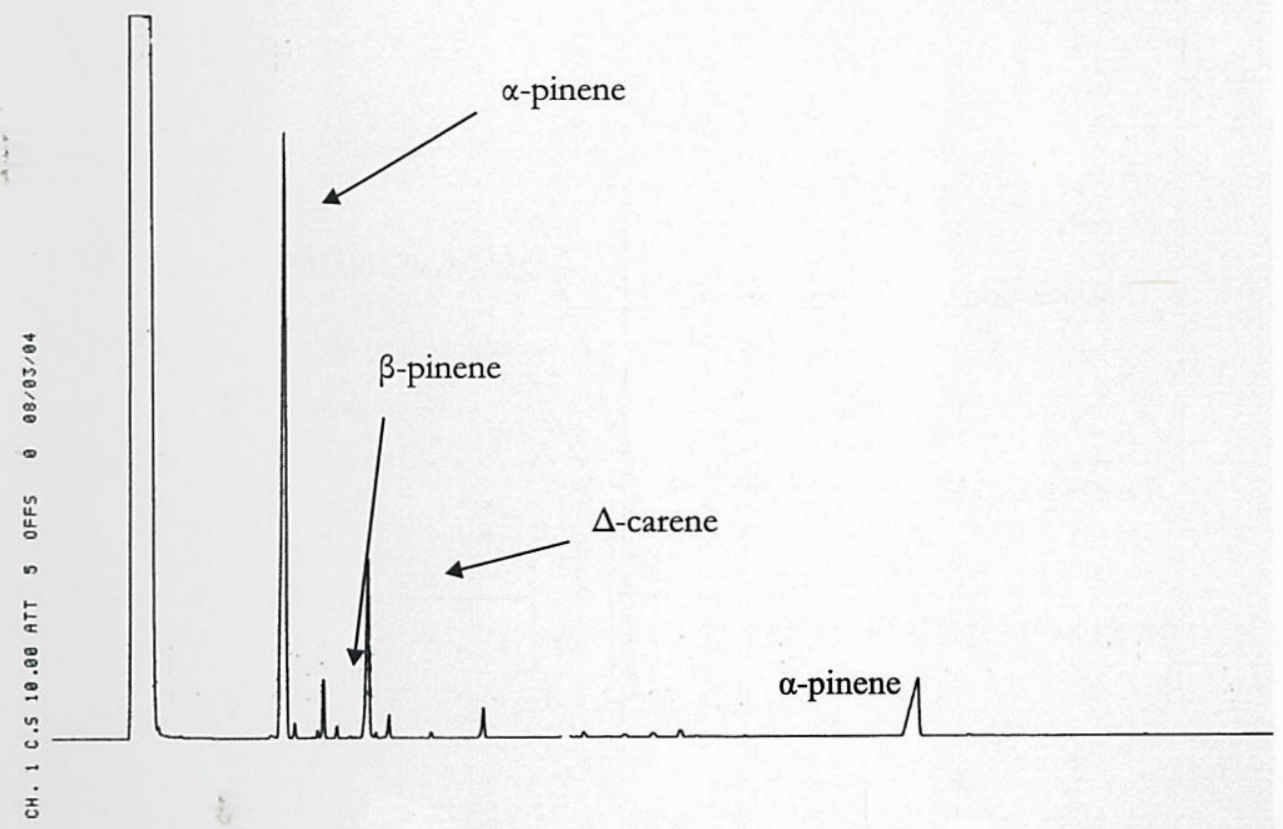


Appendix 3. Chromatogram of chemical composition of rosin

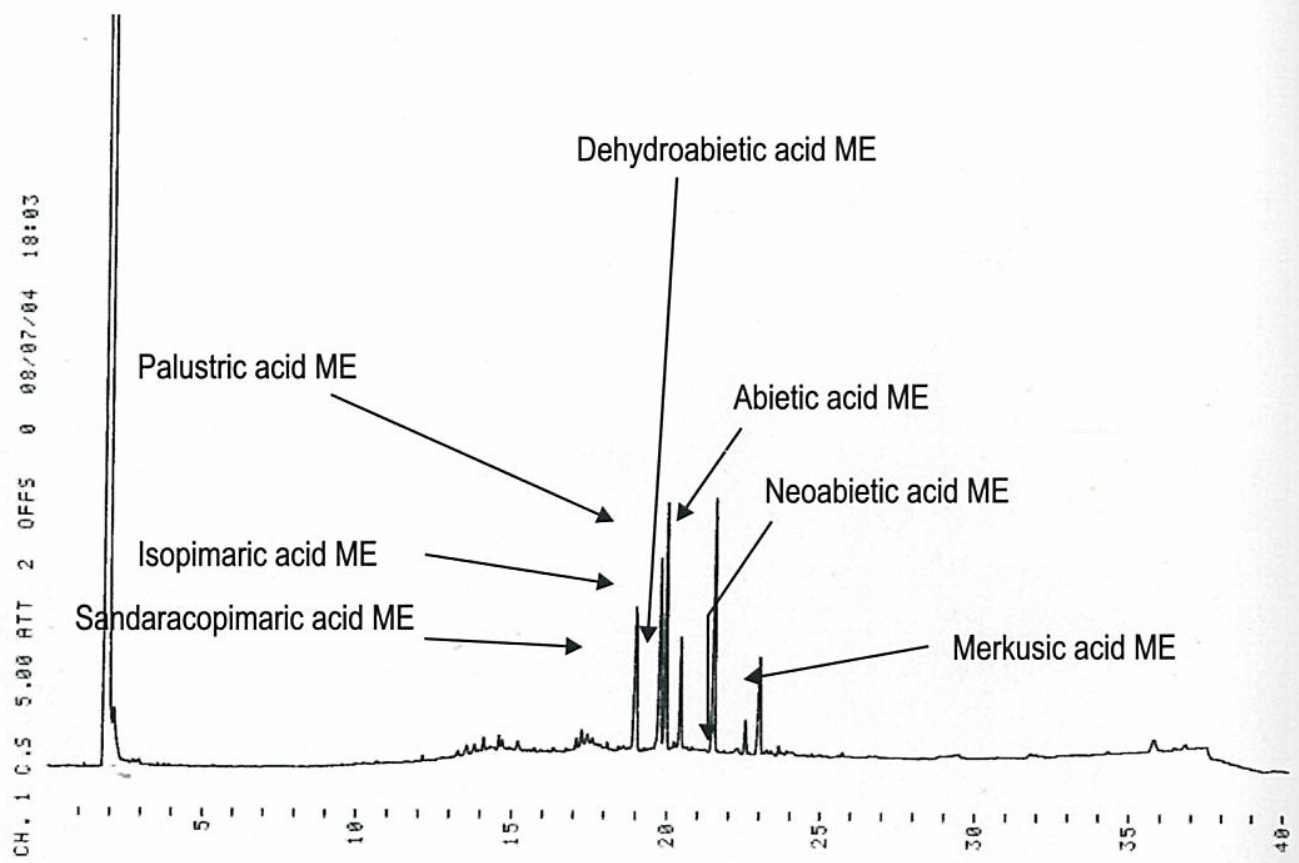

Appendix 4. Chromatogram of chemical composition for acidic fraction of pine resin

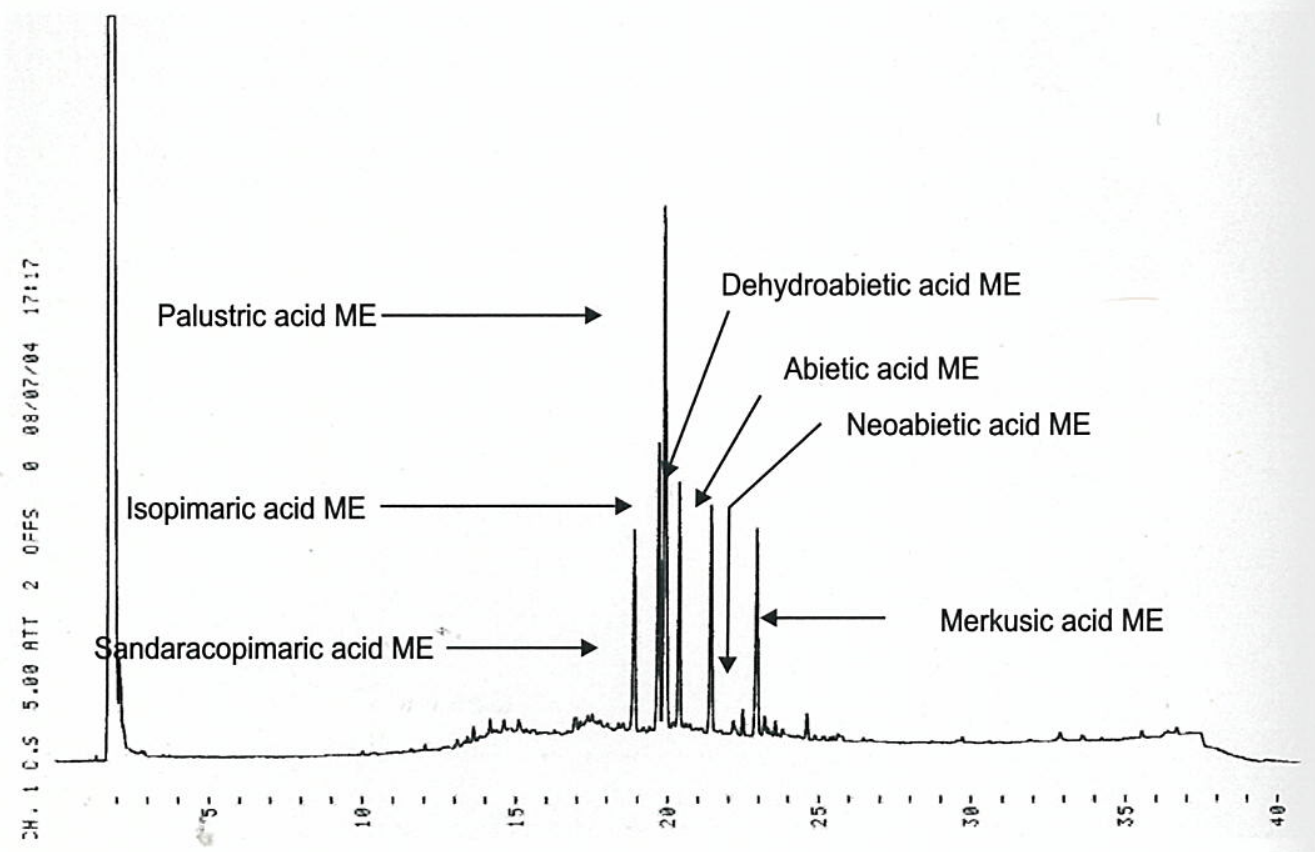


Appendix 5. A sample of identification result of a chemical component in rosin/acidic fraction through the comparing mass spectra of target compound (Palustric acid ME) to the mass spectra in the library in Gas chromatography-Spectrometry
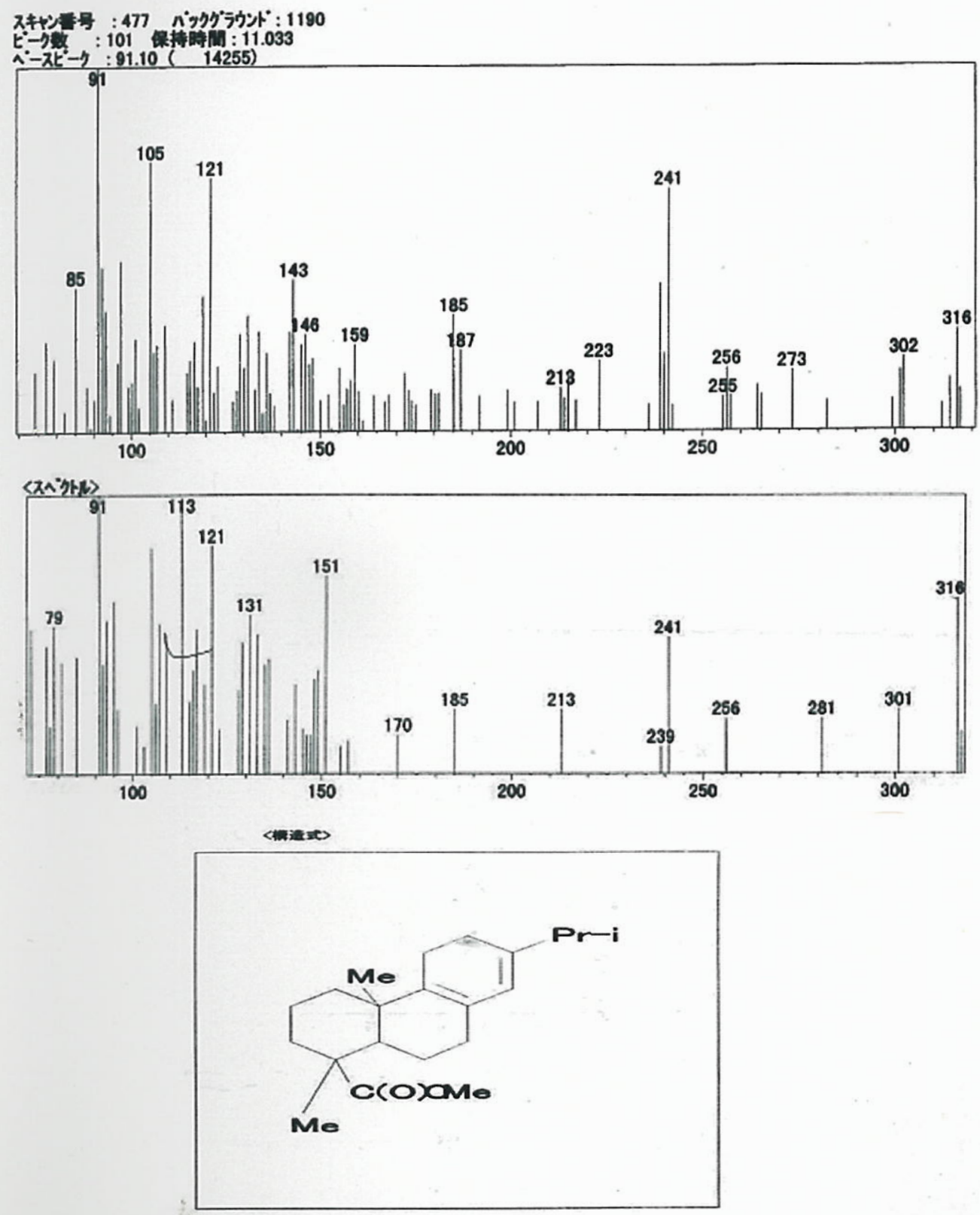
z 